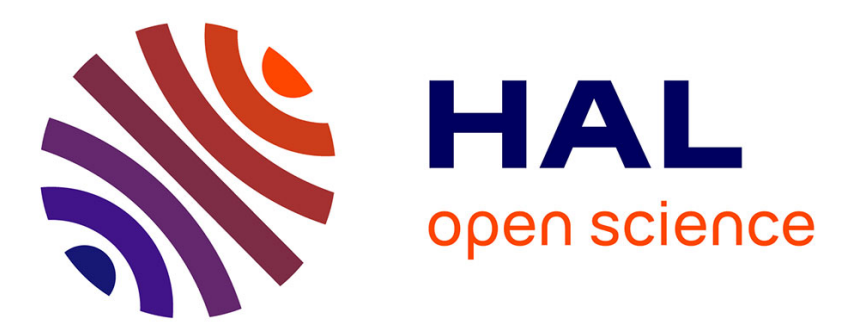

\title{
Elastomer and resin replicas for sem observation of metallic materials
}

\author{
Thierry Palin-Luc, E. Sellier, F. d'Errico, Marian Vanhaeren
}

\section{To cite this version:}

Thierry Palin-Luc, E. Sellier, F. d'Errico, Marian Vanhaeren. Elastomer and resin replicas for sem observation of metallic materials. Experimental Techniques, 2002, 26 (3), pp.33-37. hal-01372720

\section{HAL Id: hal-01372720 \\ https://hal.science/hal-01372720}

Submitted on 27 Sep 2016

HAL is a multi-disciplinary open access archive for the deposit and dissemination of scientific research documents, whether they are published or not. The documents may come from teaching and research institutions in France or abroad, or from public or private research centers.
L'archive ouverte pluridisciplinaire HAL, est destinée au dépôt et à la diffusion de documents scientifiques de niveau recherche, publiés ou non, émanant des établissements d'enseignement et de recherche français ou étrangers, des laboratoires publics ou privés. 


\section{ELASTOMER AND RESIN REPLICAS FOR SEM OBSERVATION OF METALLIC MATERIALS}

$\mathbf{T}$

he replica technique is often used to study damage evolution at the surface of specimens or industrial components and understand the physical phenomena responsible for fatigue crack initiation before failure. Replicas are usually made from acetate cellulose film. This paper presents an alternative technique generally used by archaeologists to study lithic use-wear and bone modification. A mold is made from a dental elastomer (silicon based impression material) and a positive replica is made by casting epoxy resin in the mold. Comparative SEM analysis of damaged metallic specimens and their resin replicas show that this technique provides a good resolution and preserves details up to $0.5 \mu \mathrm{m}$. This easy and low cost method allows a systematic study of micro-crack growth.

\section{Introduction}

Studying damage evolution of materials under cyclic loading is an important challenge for scientists and engineers since most structures load in this way. In the laboratory, the replica technique is used to observe damage evolution at the surface of specimens and components after different steps of loading, i.e., different cycles. Observation of replicas made after several cycles allows the monitoring of fatigue crack initiation as well as fatigue crack growth. ${ }^{1,2}$ As the first crack initiation site cannot be known in advance and looking for a small fatigue crack on a specimen surface is a waste of time, it is impractical to monitor small fatigue crack growth without a replication technique or in situ SEM observation. With an efficient replication technique, initiation sites, number of micro-cracks, crack length and growth can be quantified and their evolution versus the number of load cycles studied. This is of major importance to understand the physical phenomena responsible for fatigue damage of materials.

This paper presents a replication method inspired by a technique used by archaeologists ${ }^{3}$ to replicate bone and stone objects for SEM study. A dental elastomer is used to replicate the surface under analysis and an epoxy resin to make a three-dimensional cast. These products are described and it is explained below how to use them to obtain the best results. The cleaning procedure of the original specimen surface before molding and the preparation of replicas for SEM analysis are described, and the potential of the method discussed. The products are relatively cheap and easy to use.

\section{MATERIALS AND METHOD}

\section{Specimen and Elastomer Preparation}

The metallic specimens observed with SEM and duplicated are made of spheroidal graphite cast iron FGS800-2 (Afnor standard); details about this material and the specimens are given in Ref. 4.

T. Palin-Luc is with LAMEFIP-ENSAM, Talence Cedex, France, E. Sellier is affiiated with CREMEM-Universite Bordeaux 1, Talence Cedex, France. F. d'Errico and M. Vanhaeren are affiliated with IPGQ (UMR 5808 CNRS), Talence Cedex, France.
SEM analysis of metallic specimens requires perfectly clean surfaces. For our application we have adopted a cleaning procedure similar to that described in Refs. 3 and 5 . Traces of grease or oil are removed from the specimen with trichlorethylene or acetone and a piece of gauze. Paper handkerchief is avoided because of streaking risk. If the contamination of the surface is high and the size of the specimen compatible with its use, an ultrasonic cleaning may be very effective. As suggested by $\operatorname{Rose}^{3}$, the ultrasonicator is run for periods of one minute until the surface is clean. The final cleaning is achieved by projecting trichlorethylene onto the specimen which is subsequently dried with a hair-dryer. On line compressed air should be avoided since it may contaminate the specimen surface with oil particles. Direct contact of the specimen with fingers is to be avoided during the last stage of cleaning. Before replication, specimens are stored in airtight boxes or plastic bags to isolate them from contaminants in the air.

The following three elastomers were used to test the quality of their replicas for microscopic analysis of metallic specimens: Provil Novo Light, Impregum F and Coltène Président Light Body. The corresponding companies and addresses are given in Table 1 . These elastomers are usually used in dentistry to mold teeth.

Clear instructions on how to prepare these elastomers are given by each supplier in a technical note accompanying the product. Proportion of elastomer and catalyst should be carefully respected to produce high quality molds. At room temperature, the mixing time of the two constituents is approximatively 30 seconds. Though very simple to use, this replication technique requires some precautions. Since the viscosity of these elastomers is low, the flow of elastomer out of the molded area should be limited. ${ }^{6}$ This is achieved in our case by fixing two plates on both sides of the specimen.

Table I-Products Used

\begin{tabular}{ll}
\hline \multicolumn{1}{c}{ ELASTOMER NAME } & COMPANY NAME AND ADDRESS \\
\hline Provil Novo Light & Heraeus Kulzer \\
& D-4I538 Dormagen, Germany \\
Impregum F & ESPE \\
& Dental-Medizin GmbH \& Co. \\
& KG, \\
& D- 82229 Seefeld, Germany \\
Coltène Président Light Body & Coltène AG, \\
& Feldwiesenstrasse 20, CH-9450 \\
& Altstatten, Switzerland \\
\hline
\end{tabular}


Next, the specimen is put horizontally and the molding material applied with a syringe. The elastomer is immediately flattened with a flexible painting knife in order to eliminate air bubbles at the contact of the replicated surface. The object and the elastomer are left under a desk light for five minutes to facilitate the hardening of the product. Once this delay is over, the replica is separated from the original by hand. Finger contact with the replicated area and pollution by dust particles must be avoided during this operation. The removal of the elastomer is much easier than with acetate cellulose film because of the flexibility of the elastomer. Complex shapes can be duplicated this way. However one should be careful not to bend nor twist the replica too much as this may create micro-cracks in the replica and make it unsuitable for observation. The replica is stored in an airtight box for 48 hours before casting it, which allows gas to be given off by the elastomer.

\section{Casting}

To facilitate SEM analysis of the replicated surface, a positive replica is made by casting resin into the elastomer. This technique allows us to observe the specimen surface easily, count its defects and identify its constituents. It provides the actual morphology of the specimen surface thus avoiding the tedious and tiring exercise of reconstructing mentally positive features from their negative imprints. Furthermore, an effective metallization of the elastomer is difficult to perform.

Positive replica is made by using an epoxy resin as suggested by Rose. ${ }^{3}$ We choose the resin according to the following specifications: (i) the positive must be removed from the elastomer without altering its microscopic features, (ii) it must show a minimum amount of shrinkage and distortions, and (iii) it should represent a very accurate reproduction of the negative replica. The resin used in the frame of this work, which matches these requirements, is the RBS resin used with the RBS catalyst (T2L Chimie S.A., Z.I. la Plaine, F11500 Quillan, France). ${ }^{7}$ This low cost transparent resin has a low viscosity $\left(2300 \mathrm{mPa} . \mathrm{s}\right.$ at $\left.25^{\circ} \mathrm{C}\right)$ which is an important factor for detail rendering.

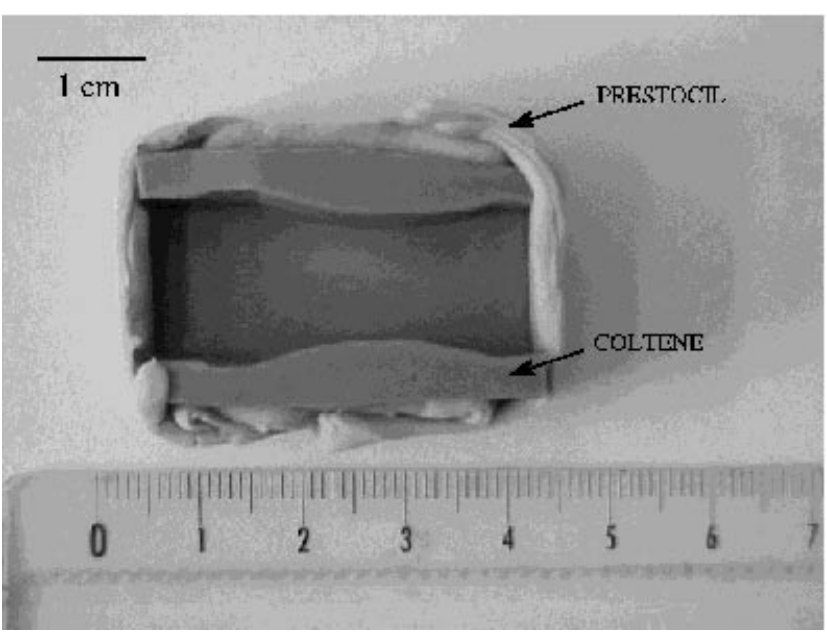

Fig. I: Elastomer replica made of the Coltène Président Light body product and its ring of Prestocil before casting

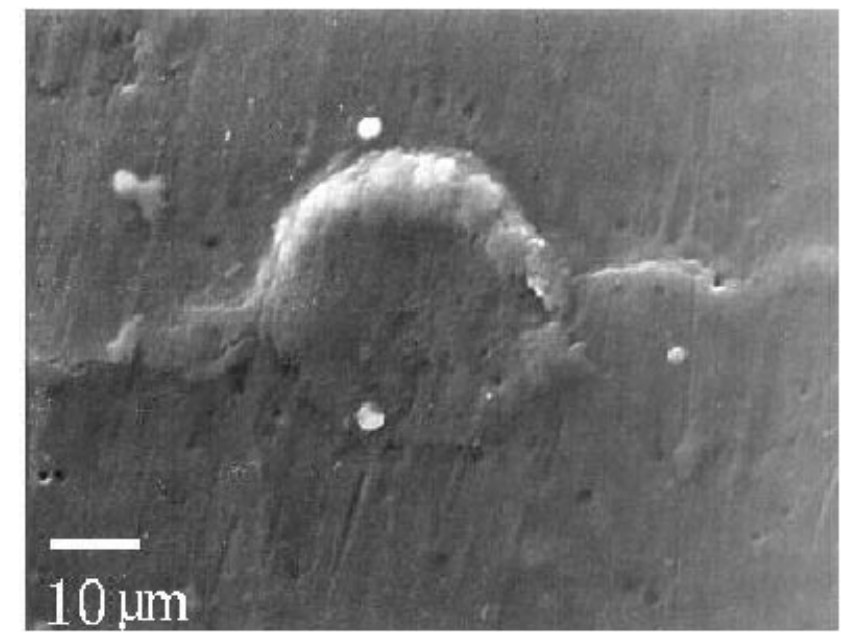

Fig. 2: Positive resin replica made from a Provil Novo Light replica

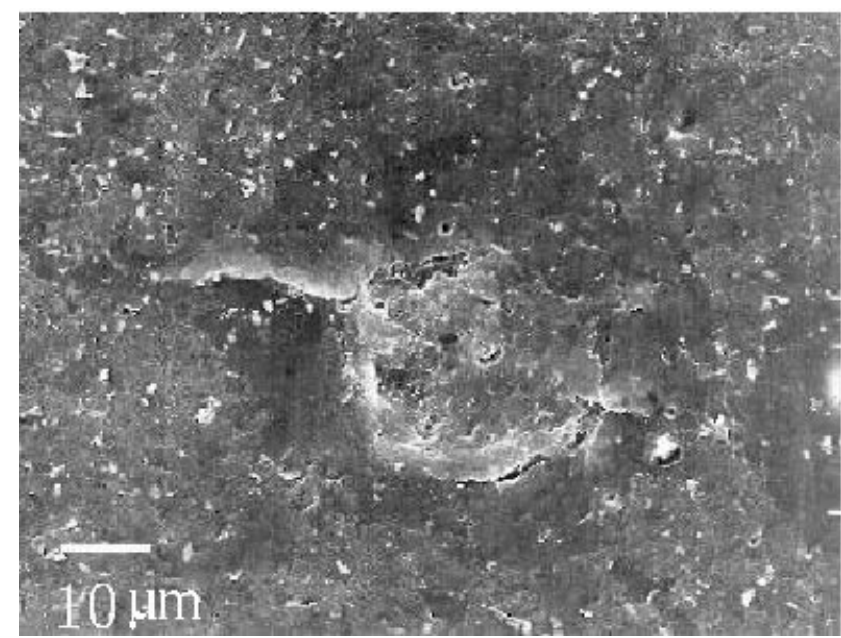

Fig. 3: Positive resin replica made from an Impregum F replica

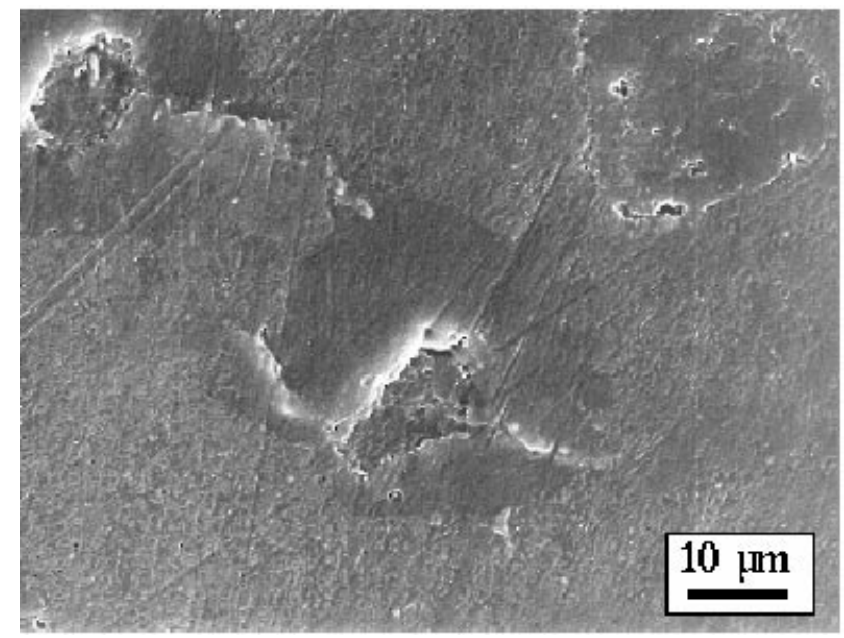

Fig. 4: Positive resin replica made from a Coltène President Light Body replica 

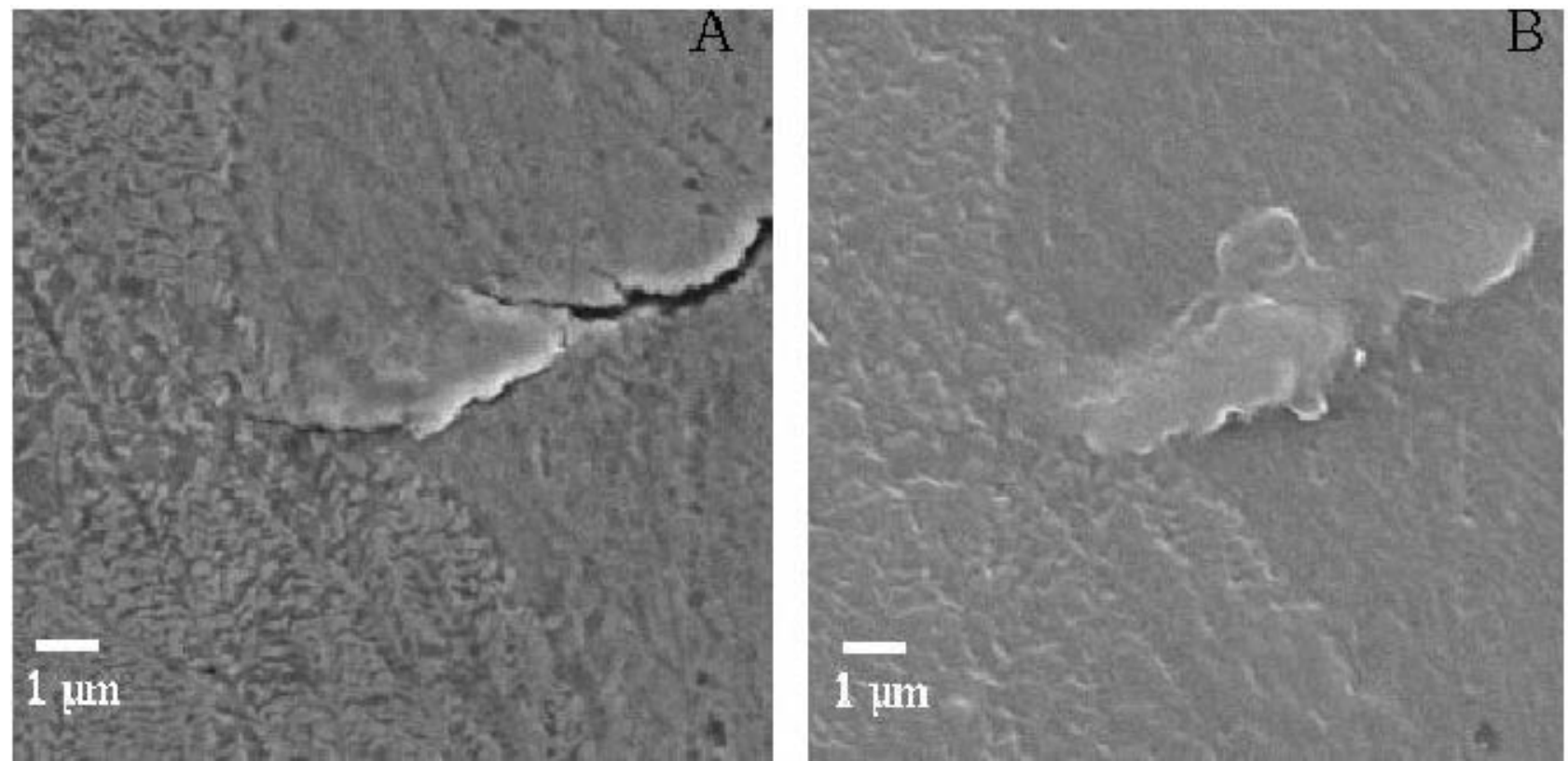

Fig. 5: Comparison between the specimen (A) and the elastomer replica (B)
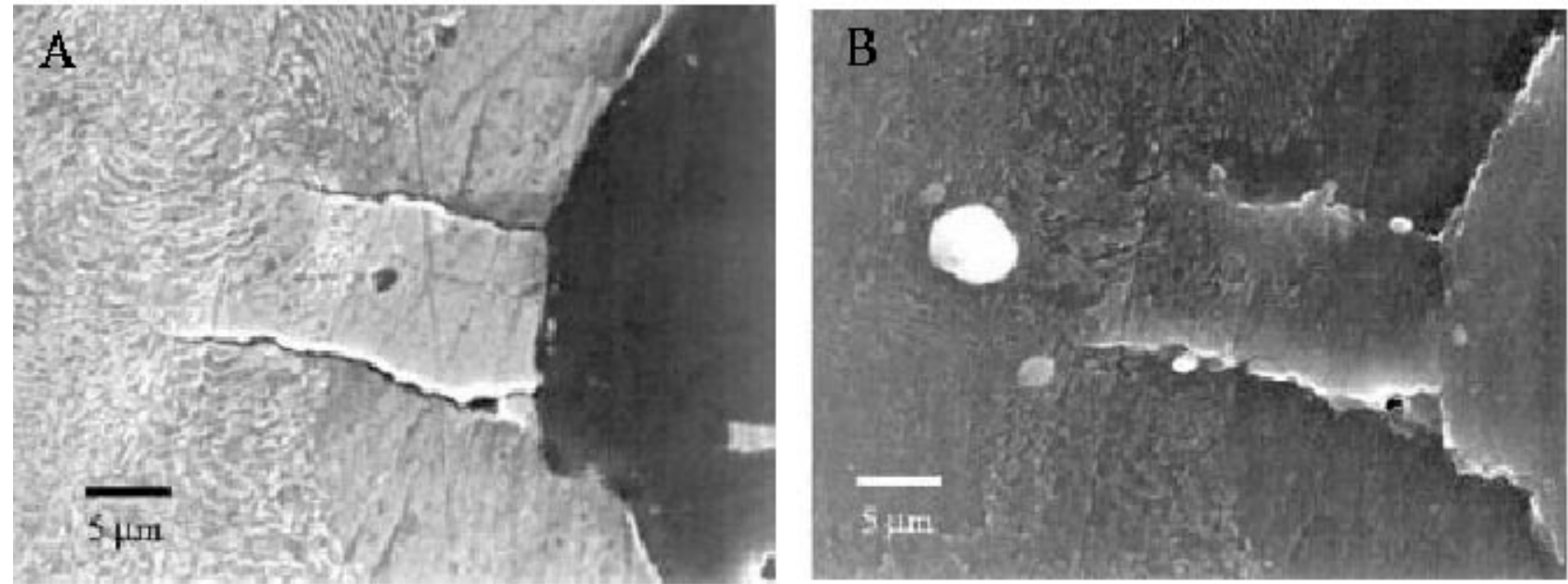

Fig. 6: Micro-crack and the three phases of the spheroidal graphite cast iron: graphite nodule, ferrite and pearlite matrix. (A) on a specimen, (B) on an elastomer positive replica. The white mark on the replica (B) is a dust particle
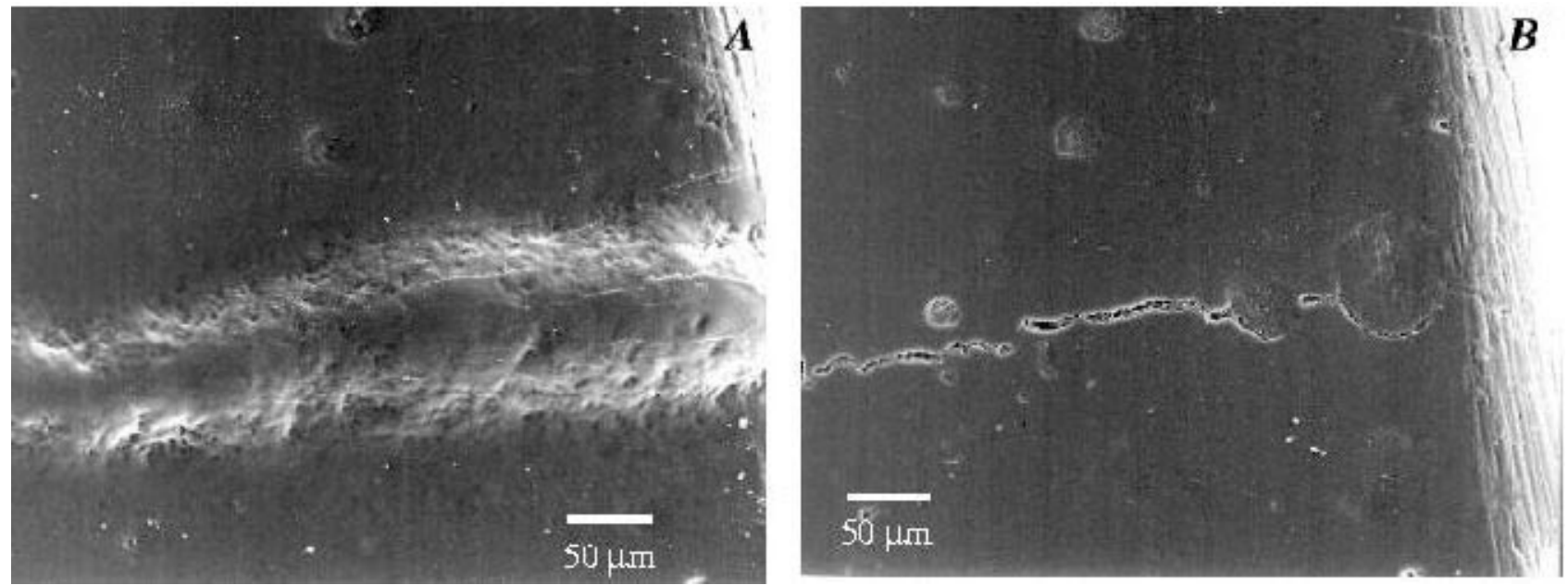

Fig. 7: Positive resin replica with artifact (A) -due to bad drying of the specimen surface- and without artifact (B) 
To reinforce the walls of the elastomer replicas and to retain the resin, a ring of another more rigid elastomer is made (Fig. 1) using the Prestocil silicon-based dental elastomer (Dental Dépot Océan, Chemin de Bragues, F-33170 Gradignan, France). This is a two component silicon based elastomer paste also used in dentistry. It has a mixing time of approximately 30-45s and a working time of approximatively $1-1 \mathrm{mn} 30 \mathrm{~s}$. It partially hardens after 4 minutes; complete hardening occurs after 24 hours. The resin can then be cast into the mold (elastomer replica and ring of Prestocil).

Preparation of the epoxy resin is performed according to the manufacturer's technical data sheet. The most important point for good quality positive replicas is to mix it thoroughly. As noticed by $\mathrm{Rose}^{3}$ and $\mathrm{d}^{\prime} \mathrm{Errico}^{6}$, air-bubbles are incorporated in the epoxy resin during mixing and, after casting, may remain stuck to the elastomer surface resulting in voids on the positive. To avoid this, we use the casting technique described by d'Errico ${ }^{6}$ to study lithic use-wear and bone damages. The epoxy resin is gradually poured into the mold by dropping the resin from a height of approximatively one meter. The viscosity of the resin and its density lead to the creation of a thin thread of resin. Air bubbles with a diameter larger than this thread disappear. To be fully cured, the resin is left 24 hours at $23-25^{\circ} \mathrm{C}$. Before removing carefully the positive replica from the mold one must check that the resin is not tacky to the touch. The positive replica has to be kept far from dust particles and not to be touched with fingers. We recommend storing replicas in an airtight box.

\section{SEM OBSERVATION}

Preparation of resin replica for SEM observation does not substantially differ from the one used to analyze other kinds of samples with this equipment. Since observation with SEM requires conductive samples, resin replicas are coated under vacuum with gold-palladium. Then they are mounted on stubs. A bridge of silver lac is put at the interface replicasupport to further improve electrical conductivity. We obtain good quality images observing the replicas at a voltage of $15 \mathrm{kV}$ and taking micrographies as secondary electron images (SEI). Observing positive resin replicas is easier and more reliable than analyzing negative elastomers. In our experience, metal-coating under vacuum of the latter produces micro-cracks, which are often difficult to distinguish from load-induced damages and thus constitute a potential source of mistake.

\section{RESULTS AND DISCUSSION}

As clearly demonstrated by Figs. 2, 3 and 4, the replicas made with Coltène light body elastomer provide the best resolution. These differences do not necessarily depend on the quality of the elastomer. They may be due to incompatibility between elastomer and resin. This might well be the case for Impregum F since, as shown in Fig. 3, the surface of its resin replica is covered with elastomer particles which have been torn off by the removal from the mold. In the following, elastomer replicas have been made of Coltène.
Figure 5, which compares the same detail on the specimen and the replica made of Coltène elastomer and RBS resin, allows us to fully appreciate the excellent resolution provided by the technique tested in the present study. Both images retain details up to $0.5 \mu \mathrm{m}$, i.e., the features required for SEM observation and quantification of damages on metals. This indicates that we can, by this means, reliably follow and record damage evolution of such materials under cyclic loadings. The three phases of the spheroidal graphite cast iron, ${ }^{4}$ for example, may be easily identified on Figure 6 . The pearlite micro structure of the matrix, the two micro-cracks, and the ferrite around the graphite nodule are as clear on the actual specimen (A) as on the replica (B).

Artifacts on the replica may be successfully avoided by carefully following the replication protocol described above. Figure $6 \mathrm{~B}$ shows pollution by a dust particle. Figure 7A illustrates the consequence on the replica of an insufficient drying of the trichlorethylene used to clean the specimen surface. Evaporation of the trichlorethylene kept in a crack produces a groove-like artifact which is absent on the replica produced with an elastomer taken after a complete drying of the specimen (Fig. 7B).

If used with some precautions, the technique we propose here is particularly appropriate to follow damage on the surface of specimens or components under cyclic loading. Due to the low stiffness of the elastomer, removing the negative replica from the duplicated surface is easier than with acetate cellulose films, the material usually used for duplicating metal surfaces. ${ }^{1,2}$ Elastomer can be successfully used even when the replicated surface has a complex morphology, which often produces the tear of the acetate cellulose peels. Furthermore, the products are low cost and easy to use.

\section{CONCLUSION AND PROSPECTS}

We have tested the reliability for mechanics studies of a technique currently used by anthropologists and archaeologists to investigate micro damage on archaeological materials [8]. This low cost and easy to use technique provides the resolution required for many laboratory observations of damage initiation and growth on metals (details up to $0.5 \mu \mathrm{m})$. Due to the low stiffness of the dental elastomer used to make the negative replica, surfaces with a complex shape can be replicated. We have demonstrated the relevance of this technique to analyze damage growth at the surface of spheroidal graphite cast iron specimens under cyclic loadings. Future studies must check the reliability of this technique on other metals such as steels, aluminium alloys, and titanium alloys. Results presented in the framework of this study, however, are promising.

\section{References}

1. Hua, C.T., and Socie, D.F., "Fatigue Damage in 1045 Steel Under Constant Amplitude Biaxial Loading," Fatigue Engng Mater. Struct., 7(3), 165-179 (1984).

2. Clément, P., Angeli, J-P., and Pineau, A., "Short Fatigue Crack Behaviour in Nodular Cast Iron," Fatigue Engng Mater. Struct., 7(4), 251-265 (1984). 
ELASTOMER AND RESIN

REPLICAS FOR OBSERVATION

3. Rose, J.J., "A Replication Technique for Scanning Electron Microscopy: Applications for Anthropologists," American J. Physical Anthropology, 62, 255-261 (1983).

4. Palin-Luc, T., Lasserre, S., and Bérard, J-Y., "Experimental Investigation on the Significance of the Conventional Endurance Limit of a Spheroidal Graphite Cast Iron," Fat. Fract. Engng. Mater. Struct., 21(3), 192-200 (1998).

5. Bromage, T.G., "The Scanning Electron Microscopy Replica Technique and Recent Applications to the Study of Fossile Bone," Scanning Microscopy, 1(2), 607-613 (1987).
6. D'Errico, F., "Traces d'Usure sur l'Industrie Lithique : Approche Méthodologique et Proposition d'Une Technique," L'Anthropologie (Paris), 89(4), 439-456 (1985).

7. D'Errico, F., "Nouvelles Observations sur Deux Pièces en Silex et un Objet en Os de la Grotte du Vallonet (Alpes-maritimes)," L'Anthropologie (Paris), 92(2), 615-628 (1988).

8. D'Errico, F., "The Use of Resin Cast for the Study of Usewear," Scanning Electron Microscopy in Archaeology, Olsen, S.L., editor, British Arch. Reports Int. series, pages 155-167, 452 Oxford (1988). 